\title{
Agility and Responsiveness Capabilities: Impact on Supply Chain Performance
}

\author{
Aziz Barhmi (PhD) \\ Ibn Tofail University, Kénitra, Morocco
}

Doi:10.19044/esj.2019.v15n7p212～ＵRL:http://dx.doi.org/10.19044/esj.2019.v15n7p212

\begin{abstract}
This paper focuses on exploring the mediation role of supply chain responsiveness, supply chain agility, and supply chain performance link through a multi-disciplinary review of the relevant research. The systematic literature review aims to provide the basis for formulating a conceptual framework of the relationships. A systematic comprehensive review of the literature on supply chain agility, supply chain responsiveness, and supply chain performance was conducted. The dynamic capabilities perspective literature was also examined to identify the theoretical basis for the contribution of supply chain agility in improving supply chain performance by reconfiguring supply chain responsiveness. The supply chain agility has been mainly explored in the literature with emphasis on the dimensions of the concept. The role of the supply chain agility, as a dynamic capability, in the reconfiguration of the supply chain responsiveness is seen in its quality of operational capability and, consequently, in the improvement of the performance of the supply chain in general.
\end{abstract}

Keywords: Dynamic Capabilities Perspective, Supply Chain Agility, Supply Chain Responsiveness, Supply Chain Performance

\section{Introduction}

During the past few decades, interest in supply chain agility (SCA) by research scholars has increased substantially (Chan et al., 2017). Previous studies have advanced empirical evidence of the positive relationship between the agile supply chain and competitive advantage (Wu Tseng, Chiu, \& Lim, 2017); handling uncertainties (Gligor, Esmark, \& Holcomb, 2015); reducing lead time (Chan et al., 2017); and value differentiators (Khan \& Pillania, 2008) in a way which leads to higher supply chain performance (SCP). However, the SCA as a dynamic capability has a significant impact on the SCP through the reconfiguration of the supply chain responsiveness (SCR) as an operational capability. 
To this end, agility has been identified as one of the most important issues in contemporary supply chain management (SCM) (Gligor \& Holcomb, 2012a). Companies operate in the context of dynamic global supply chains where "It's not the big that eats the small...It's the fast that eats the slow" (Jennings \& Haughton, 2002). While the benefits of agility have been documented in a variety of areas (Zhang, 2011), there is little empirical research addressing the impact of SCA on business performance (Gligor \& Holcomb, 2012b).

In addition, to respond effectively to today's market dynamics, organizations must be operationally flexible in many ways. Previous research has identified different types of flexibility associated with SCR, including new product flexibility, volume flexibility, variety flexibility, and modification flexibility (customization). This is reflected in the overall SCR allowing organizations and their supply chains to align supply with demand requirements in an adequate way (Malhotra \& Mackelprang, 2012).

However, in accordance with the principles of the dynamic capabilities perspective (DCP), there is a distinction between dynamic capabilities and ordinary or operational capabilities. Operational capabilities enable an organization to survive, while dynamic capabilities alter how an organization achieves survival (Helfat \& Winter, 2011). Dynamic capabilities allow the company to change the resource base, change operational capabilities, and/or initiate a change in the organization's external environment (Barrales-Molina et al., 2014).

To this end, it appears that one of the main objectives of the SCA, as a dynamic capability, is to reconfigure the SCR as an operational capability and to achieve superior performance. Consequently, it also provides a sustainable competitive advantage both for the supply chain and the companies that make it up.

Although many previous studies have shown direct, positive, and significant effects between the SCA and the performance of the company, it seems appropriate to study the effects between the SCA and the SCP through the SCR, from a supply chain perspective and not a business perspective. Therefore, one of the current issues of contemporary SCM is: How does SCA affect the SCP through the reconfiguration of SCR? This article aims to clarify this issue.

The following part of the paper has been organized in different sections to deal with the subject. Section 2 conceptualizes the constructs. Section 3 proposes the hypotheses as well as the conceptual model of the research. Section 4 concludes with the theoretical and managerial implications of this research. 


\section{Theoretical Background}

\section{- Dynamic Capabilities Perspective}

The DCP is a widely applied paradigm to explain variance in performance across competing firms (Barreto, 2010). With its roots in resource-based view (RBV), this theoretical perspective argues that superior firm performance comes from two types of organizational capabilities, namely, dynamic capability and operational capability (Cepeda \& Vera, 2007). The literature formulated the basic difference between dynamic capability and operational capability (Kabadayi, 2011). As such, researchers have distinguished between dynamic capabilities and ordinary capabilities. Ordinary or operational zeroorder capabilities enable an organization to survive, while dynamic capabilities alter the way an organization obtains its survival (Helfat \& Winter, 2011). Dynamic capabilities allow the company to change the resource base, change operational capabilities, and/or initiate a change in the organization's external environment (Teece, 2007). Helfat et al. (2007) defined dynamic capabilities as the "ability of an organization to deliberately create, extend, or modify its resource base" (p.4).

In this paper, the DCP is used to explain the impact of SCA as a higher order dynamic capability that improves the SCP and, therefore, gains competitive advantage through reconfiguration of operational capabilities, including SCR. In support of the DCP, this paper proposes that the SCA brings about a positive change in SCP. This impact of SCA is mediated by the SCR.

\section{- Supply Chain Agility}

The shift from enterprise to supply chain competition has increased the need to better understand the determinants that lead to successful results for the entire supply chain and not just for individual members. According to Agarwal et al. (2006), "SCM helps companies integrate their activities, working with other value chain partners, to meet the unpredictable end-user demand' '(p.221). The premise of the authors is that an integrated supply chain is needed to cope with the uncertainty of demand. In addition, they argued that non-integrated manufacturing processes, non-integrated distribution processes, and poor supplier and customer relationships will lead to failure. Thus, agility has been suggested as a means by which the supply chain is able to adapt to the changing needs of the market (Jain et al., 2008).

Furthermore, studies on SCA can be divided into two heads. One considers SCA to be a supply chain-wide capability (Gligor \& Holcomb 2012b) drawing strengths from inter-organisational relationships; the other considers SCA to be an organisational capability that manages itself and has the competence to collaborate with others (Brusset, 2016). However, this is to enable them cope with volatility. 
Given the objectives of this article, SCA is defined as a higher order dynamic capability that assists organizations as well as the supply chain as a whole to quickly sense and respond to internal and external changes, either proactively or reactively, leveraging through the reconfiguration of the SCR as a collective operational capability.

In addition, current research develops a comprehensive conceptualization and measurement scale of SCA that explores the multi-dimensionality of the concept. As such, the fundamental theories of social science and life science have identified five dimensions of SCA, including alertness, accessibility, determination, swiftness, and flexibility.

\section{- Supply Chain Responsiveness}

The literature on operations management has increasingly invoked the term responsiveness (Holweg, 2005). Gindy et al. (1999) referred to responsiveness as the ability of a manufacturing system to make quick and balanced adjustments to the predictable and unpredictable changes that characterize today's manufacturing environment. These authors focused on the internal conditions of the plant and the internal operating results. Barclay and Dann (1996) defined responsiveness as the ability to respond deliberately and in a timely manner to significant events and opportunities or threats to gain/maintain a competitive advantage. They also defined the responsiveness capability as the degree of responsiveness that a company owns or needs. In other words, it is the ability to react and/or predict events in order to manage, control, and profit from them. However, it is important to note that these authors used the terms "responsiveness" and "agility" interchangeably in their study.

In addition, Holweg (2005) presented one of the seminal attempts to differentiate between responsiveness and flexibility. His discussion was then among the few in the operations management literature to explicitly recognize the client or the market as part of the field of responsiveness. He also articulated and empirically identified three determinants of SCR, which he called "dimensions of responsiveness". More recently, Reichhart and Holweg (2007) found that most authors seem to link reactivity exclusively to external events and concluded that responsiveness should be viewed as a concept that is solely client-driven. Therefore, they defined responsiveness as the speed with which a system can adjust its output within the available range of four types of flexibility (product, mix, volume, and delivery) in response to an external stimulus. This notion of stimulus (the client) resonates with one of the main components of the reactivity (stimuli), which is identified by Kritchanchai and MacCarthy (1999). Most of the explicit and available definitions in the reactivity literature contain the notion of stimuli. This component is explicit in the definition of Reichhart and Holweg (2007) and 
implicit in terms, such as the need or desire of the client (Tunc \& Gupta, 1993), demand (Holweg, 2005), control (Upton, 1995) and the market signal (Catalan \& Kotzab, 2003). Another major component of most definitions is the notion of time, which is explicitly captured by the term time (Catalan \& Kotzab, 2003) and implicitly grasped by the terms speed (Reichhart \& Holweg, 2007) and timeliness (Upton, 1995).

Given the context of this research, we have endorsed the definition of Reichhart and Holweg (2007). Therefore, we clarify the connotation of the SCR concept in terms of four flexibilities, including volume, variety, new product, and modification (customization).

\section{- Supply Chain Performance}

To achieve their goals, organizations must keep the supply chain under control and manage processes that often go beyond their limits (Brewer \& Speh, 2000). Given that organizational performance is increasingly dependent on supply chain partners ( $\mathrm{Li}$ et al., 2005), there is no need to broaden the vision of management and control through the supply chain (Mentzer et al., 2001). The SCM seeks to improve performance through the effective use of resources and capabilities and the development of internal and external links, therefore creating a perfectly coordinated supply chain (Ketchen \& Hult 2007). To this end, the performance measurement systems (PMS) of the supply chain make it possible to adopt performance indicators covering different companies and processes. Therefore, PMS represents a way to improve supply chain governance by ensuring more relevant, aware, and timely decisions (Gunasekaran et al., 2004).

As a result of the complexity of supply chains, compiling and delineating performance metrics is a difficult task (Shephard \& Günter, 2006). Many researchers have tried to systematically collect measurements to evaluate SCP. In addition, the critical issues related to the measurement of SCP are:

- Lack of consideration of supply chain and supply chain relationships as a whole (Lambert \& Pohlen, 2001). However, the management of the performance of the entire supply chain is, in fact, very difficult and could be non-existent (Banomyong \& Supan, 2010).

- The shortage of qualitative metrics and non-financial measures of innovation and customer satisfaction should also be addressed.

- Human resource management and modern manufacturing practices should be included in the design of a supply chain PMS.

- The factors that influence the success or failure of the PMS attempt for the supply chain should be investigated.

In order to improve SCP, it is necessary to have a PMS that integrates the different aspects of performance into a cohesive system. This is because such an integrated system improves the flow of information within the supply chain. 
According to Bititci et al. (1997), the integrated PMS is an information system at the heart of the performance management process, and it is crucial for the efficient and effective functioning of the PMS. More so, integrated PMS provides a more complete measure of total SCP.

\section{Hypotheses and Conceptual Model Development}

SCA can be seen as a source of competitive advantage resulting from idiosyncratic business-to-business linkages or knowledge sharing routines. SCA can also be considered as a dynamic capability. Although several conceptualizations of the concept were later introduced (Barreto, 2010), dynamic capabilities were originally defined as "the firm's ability to integrate, build, and reconfigure internal and external competencies to address rapidly changing environments" (Teece et al., 1997, p.516). SCA can be conceptualized as a dynamic capability for several reasons, including meeting the higher level capability criterion (Winter, 2003). It is dedicated to the modification of the operating routines (Zollo \& Winter, 2002). It also facilitates resource reconfiguration and enables sensing and capitalizing on environmental threats and opportunities (Teece, 2007).

Dynamic capabilities can also take on several forms. In the context of a stable industry structure, they resemble the traditional conception of routines. That is, they are complicated, detailed, and involve analytic processes that rely extensively on existing knowledge to yield predictable outcomes. However, within the context of high-velocity markets, dynamic capabilities are simple, experiential, and involve unstable processes that rely on rapidly created new knowledge to produce unpredictable outcomes (Eisenhardt \& Martin, 2000). SCA relies on lower-order dynamic capabilities, primarily information technology capabilities, communication, collaboration, and coordination capabilities among members of the supply chain (Allred et al., 2011). Since dynamic capabilities are difficult to replicate, they enable firms to achieve higher levels of performance (Dyer, 1996).

SCA calls for specific investments to reap the benefits of customisations, flexibility, and responsiveness to changes in business environments. Therefore, the collaboration between the supply chain partners fostered by SCA acts as safeguards against opportunistic behaviour and allows for transactions, thus, economising on bounded rationality (Yang, 2014). Therefore, the transaction cost and resource consumptions are reduced, leading to higher performance. Transaction cost economics advocates that SCP can be improved by reducing the uncertainty and conflict in the supply chain relationship. SCA creates value within supply chain through cost efficiency (Croxton, Garcia-Dastugue, Lambert, \& Rogers, 2001). The same is achieved through logistics/transportation activities to improve profits, sales, inventory turnover, and better customer satisfaction (Halley \& Guilhon, 1997). 
In addition, SCA allows better allocation of the resources and costs leveraging to create value for the final customer, ultimately resulting in superior performance (Langley \& Holcomb, 1992). Hence, we propose that:

\section{H1. SCA is positively related to SCP}

Firm performance refers to how well a firm achieves its market-oriented and financial goals ( $\mathrm{Li}$ et al., 2006). Improving SCP has been considered an effective means for improving organizational performance (Gunasekaran et al., 2008). Wu et al. (2006) argue that higher levels of supply chain capabilities (exemplified by supply chain responsiveness, information exchange, coordination, and interfirm activity integration) can potentially improve a firm's market and financial performance. Lao et al. (2010) suggest that the higher the supply chain flexibility, the better it is at enabling the focal firm to adapt to changes in the market. Thus, we hypothesize in $\mathrm{H} 2$ that the ability of the supply chain to respond effectively to customers' demand is positively related to SCP. Therefore, it is hypothesized that:

\section{H2. SCR is positively associated with SCP}

The goal of the DCP is to explain the sources of competitive advantage (Teece et al., 1997). This means that business performance is a key component of DCP and is generally considered the ultimate goal of dynamic capabilities. According to this perspective, dynamic capabilities, especially the SCA, modify the ordinary capacities, in this case, the SCR or the broader base of resources of the company. This change may ultimately result in a change in performance. Therefore, dynamic capabilities cannot explain performance, but rather performance changes.

Accreditation of performance according to the dynamic capabilities of firms (Priem \& Butler, 2001) has been widely criticized. To overcome this limitation, several researchers have suggested that dynamic capabilities should be observed by changes in a firm's resource base or operational capabilities (Teece, 2007). These changes may or may not improve the performance of the company. As a result, having dynamic capabilities does not necessarily lead to higher performance. Nevertheless, performance depends on the quality of operational capabilities that dynamic capabilities change (Zahra et al., 2006) and the scalability of such capabilities (Helfat et al., 2007). The superior dynamic capability related to the SCA cannot lead to superior performance if the operational capability which is inherent to SCR customers is significantly lower.

In addition, we suggest that the SCR, as a collective operational capability reflecting the ability of a supply chain to respond to the four types of flexibilities (volume, variety, new product, and modification), is an important mediator, affecting the impact of SCA on SCP. 


\section{H3: SCR mediates the relationship between SCA and SCP}

As in previous empirical studies, this model aims to explore the existing relationships between SCA, SCR, and SCP in the context of manufacturing companies located in Morocco and belonging to the global supply chains through international transactions, including import, export and/or both.

Firstly, SCA was considered to be an independent or explanatory variable of the model with 05 dimensions:

- D01 - Alertness

- D02 - Accessibility

- D03 - Decisiveness

- D04 - Swiftness

- D05 - Flexibility

Secondly, the SCR has been incorporated into the conceptual model as a one-dimensional mediator variable between the SCA and the SCP variables.

Thirdly, the SCP was designated in the research model as a dependent variable at 02 dimensions:

- D01 - Operational Performance

- D02 - Relational performance

As such, it is important to note that SCP should measure the direct and indirect effects, respectively, of the SCA and SCR as illustrated in Figure 1.

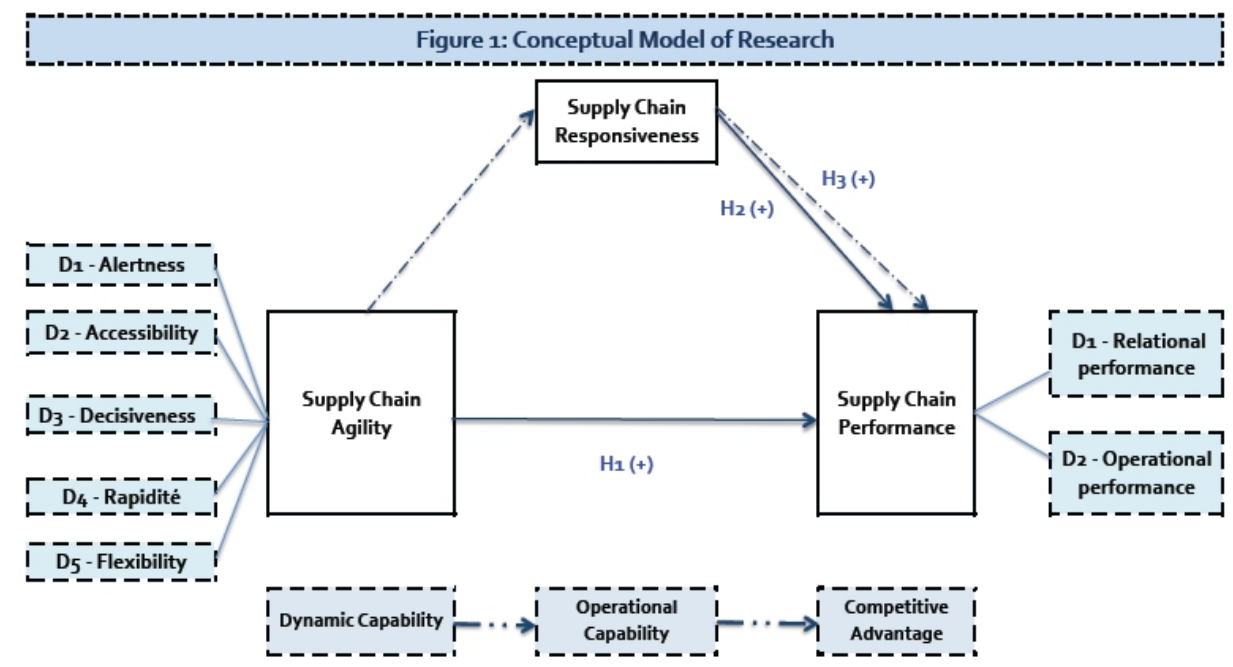

\section{Conclusion}

This paper brings a number of theoretical contributions to research. Firstly, it responds to queries for consideration of the question: how do dynamic capabilities support performance through reconfiguration and/or development of the operational capability base? Specifically, the DCP provides a framework for understanding how SCA reconfigures and/or develops SCR 
and, consequently, indirectly impacts SCP. Also, our research aims to show the mediating effect of SCR in the relationship between SCA and SCP. Although the literature deals with concepts related to agility and responsiveness in relation to business performance, this research also claims to contribute to the literature review by revealing the role of the SCA, as a dynamic capability, in the reconfiguration and/or generation of the SCR as an operational capability, and ultimately in the improvement of the SCP.

Additionally, previous research has primarily focused on the relationship between SCA and its antecedents or facilitators. The model that has been introduced in this research considers SCA as a higher-order dynamic capability which is essential to the generation and/or reconfiguration of operational capabilities, including SCR, without the consideration in the model of the lower-order dynamic capabilities called antecedent or facilitators.

To date, there is no empirical evidence in the literature to suggest that dynamic capacity development impacts the performance of global supply chains through the generation and/or reconfiguration of operational capabilities, in response to changes, opportunities and threats from the environment. For this purpose, this research demonstrates why careful consideration should be given when deciding on the choice of dynamic capabilities to develop and, therefore, the operational capabilities that will be targeted by generation and/or reconfiguration. As a result, companies that succeeds in building this relationship benefit in terms of improving the performance of both the global supply chain and its partners. This enables them to achieve a sustainable competitive advantage. This research also demonstrates that such a relationship cannot be achieved in isolation at the company level alone. It is imperative for managers to develop dynamic capabilities and reconfigure operational capabilities that are inherent in their respective global supply chains.

In addition, our research has important implications for global supply chains managers. They should be aware of the importance of dynamic capabilities in the reconfiguration and/or generation of operational capabilities directly related to performance improvement. Also, managers could identify the dynamic capability for SCA into five sub-capabilities, including alertness, accessibility, decisiveness, swiftness, and flexibility.

\section{References:}

1. Agarwal, A., Shankar, R., \& Tiwari, M. K. (2006). Modeling the metrics of lean, agile and agile supply chain: An ANP-based approach. European Journal of Operational Research, 173(1), 211225. 
2. Allred, C. R., Fawcett, S. E., Wallin, C., \& Magnan, G. M. (2011). A dynamic collaboration capability as a source of competitive advantage. Decision Sciences, 42(1), 129-161.

3. Banomyong, R. \& Supatn, N. (2011). Developing a supply chain performance tool for SMEs in Thailand. Supply Chain Management: An International Journal, 16(1), 20-31.

4. Barclay, I., Poolton, J., \& Dann, Z. (1996). Improving competitive responsiveness via the virtual environment. In Engineering and Technology Management, 1996. IEMC 96. Proceedings., International Conference on (pp. 52-62). IEEE.

5. Barrales-Molina, V., Martínez-López, F. J., \& Gázquez-Abad, J. C. (2014). Dynamic marketing capabilities: Toward an integrative framework. International Journal of Management Reviews, 16(4), 397-416.

6. Barreto, I. (2010). Dynamic capabilities: A review of past research and an agenda for the future. Journal of Management, 36(1), 256280.

7. Bititci, U. S., Carrie, A. S., \& McDevitt, L. (1997). Integrated performance measurement systems: a development guide. International Journal of Operations and Production Management, 17(5), 522-534.

8. Brewer, P. C. \& Speh, T. W. (2000). Using the balanced scorecard to measure supply chain performance. Journal of Business Logistics, 21(1), 75.

9. Brusset, X. (2016). Does supply chain visibility enhance agility?. International Journal of Production Economics, 171, 46-59.

10. Catalan, M. \& Kotzab, H. (2003). Assessing the responsiveness in the Danish mobile phone supply chain. International Journal of Physical Distribution and Logistics Management, 33(8), 668-685.

11. Cepeda, G. \& Vera, D. (2007). Dynamic capabilities and operational capabilities: A knowledge management perspective. Journal of Business Research, 60(5), 426-437.

12. Chan, A. T., Ngai, E. W., \& Moon, K. K. (2017). The effects of strategic and manufacturing flexibilities and supply chain agility on firm performance in the fashion industry. European Journal of Operational Research, 259(2), 486-499.

13. Croxton, K. L., Garcia-Dastugue, S. J., Lambert, D. M., \& Rogers, D. S. (2001). The supply chain management processes. The International Journal of Logistics Management, 12(2), 13-36.

14. Dyer, J. H. (1996). Specialized supplier networks as a source of competitive advantage: Evidence from the auto industry. Strategic Management Journal, 17(4), 271-291. 
15. Eisenhardt, K. M. \& Martin, J. A. (2000). Dynamic capabilities: what are they?. Strategic Management Journal, 21(10/11), 1105-1121.

16. Gindy, N. N., Saad, S. M., \& Yue, Y. (1999). Manufacturing responsiveness through integrated process planning and scheduling. International Journal of Production Research, 37(11), 2399-2418.

17. Gligor, D. M. \& Holcomb, M. C. (2012a). Understanding the role of logistics capabilities in achieving supply chain agility: A systematic literature review. Supply Chain Management: An International Journal, 17(4), 438-453.

18. Gligor, D. M. \& Holcomb, M.C. (2012b). Antecedents and Consequences of Supply Chain Agility: Establishing the Link to Firm Performance. Journal of Business Logistics, 33(4), 295-309.

19. Gligor, D. M., Esmark, C. L., \& Holcomb, M. C. (2015). Performance outcomes of supply chain agility: when should you be agile?. Journal of Operations Management, 33, 71-82.

20. Gunasekaran, A., Patel, C., \& McGaughey, R. E. (2004). A framework for supply chain performance measurement. International Journal of Production Economics, 87(3), 333-347.

21. Gunasekaran, A., Lai, K. H., \& Cheng, T. E. (2008). Responsive supply chain: a competitive strategy in a networked economy. Omega, 36(4), 549-564.

22. Halley, A. \& Guilhon, A. (1997). Logistics behaviour of small enterprises: performance, strategy, and definition. International Journal of Physical Distribution and Logistics Management, 27(8), 475-495.

23. Helfat, C. E. \& Winter, S. G. (2011). Untangling dynamic and operational capabilities: Strategy for the $(\mathrm{N})$ ever-changing world. Strategic Management Journal, 32(11), 1243-1250.

24. Holweg, M. (2005). The three dimensions of responsiveness. International Journal of Operations and Production Management, 25(7), 603-622.

25. Jain, V., Benyoucef, L., \& Deshmukh, S. G. (2008). A new approach for evaluating agility in supply chains using fuzzy association rules mining. Engineering Applications of Artificial Intelligence, 21(3), 367-385.

26. Jennings, J. \& Haughton, L. (2002). It's not the BIG that eats the SMALL... it's the FAST that eats the SLOW: How to use speed as a competitive tool in business.

27. Kabadayi, S., Eyuboglu, N., \& Thomas, G. P. (2007). The performance implications of designing multiple channels to fit with strategy and environment. Journal of Marketing, 71(4), 195-211. 
28. Ketchen Jr, D. J. \& Hult, G. T. M. (2007). Bridging organization theory and supply chain management: The case of best value supply chains. Journal of Operations Management, 25(2), 573-580.

29. Khan K, A. \& Pillania, R. K. (2008). Strategic sourcing for supply chain agility and firms' performance: A study of the Indian manufacturing sector. Management Decision, 46(10), 1508-1530.

30. Kritchanchai, D. \& MacCarthy, B. L. (1999). Responsiveness of the order fulfillment process. International Journal of Operations and Production Management, 19(8), 812-833.

31. Lambert, D. M. \& Pohlen, T. L. (2001). Supply chain metrics. International Journal of Logistics Management, 12(1), 1-19.

32. Langley Jr, C. J. \& Holcomb, M. C. (1992). Creating logistics customer value. Journal of Business Logistics, 13(2), 1.

33. Lao, Y., Hong, P., \& Rao, S. (2010). Supply Chain Management, Supply Chain Flexibility and Performance Outcomes: An Empirical Investigation of Manufacturing Firms. Journal of Supply Chain Management, 46(3), 6- 22.

34. Li, H. \& Zhou, L. A. (2005). Political turnover and economic performance: the incentive role of personal control in China. Journal of Public Economics, 89(9-10), 1743-1762.

35. Malhotra, M. K. \& Mackelprang, A. W. (2012). Are internal manufacturing and external supply chain flexibilities complementary capabilities?. Journal of Operations Management, 30(3), 180-200.

36. Mentzer, J. T., DeWitt, W., Keebler, J. S., Min, S., Nix, N. W., Smith, C. D., \& Zacharia, Z. G. (2001). Defining supply chain management. Journal of Business Logistics, 22(2), 1-25.

37. Priem, R. L. \& Butler, J. E. (2001). Is the resource-based "view" a useful perspective for strategic management research?. Academy of Management Review, 26(1), 22-40.

38. Reichhart, A. \& Holweg, M. (2007). Creating the customerresponsive supply chain: a reconciliation of concepts. International Journal of Operations and Production Management, 27(11), 11441172.

39. Shepherd, C. \& Günter, H. (2006). Measuring supply chain performance: current research and future directions. International Journal of Productivity and Performance Management, 55(3/4), 24258.

40. Teece, D. J., Pisano, G., \& Shuen, A. (1997). Dynamic capabilities and strategic management. Strategic Management Journal, 18(7), 509-533. 
41. Teece, D. J. (2007). Explicating dynamic capabilities: the nature and microfoundations of (sustainable) enterprise performance. Strategic Management Journal, 28(13), 1319-1350.

42. Tunc, E. A. \& Gupta, J. N. (1993). Is time a competitive weapon among manufacturing firms?. International Journal of Operations and Production Management, 13(3), 4-12.

43. Upton, D. (1995). What really makes factories flexible?. Harvard Business Review, 73(4), 74-84.

44. Winter, S. G. (2003). Understanding dynamic capabilities. Strategic Management Journal, 24, 991-995.

45. Wu, F., Yeniyurt, S., Kim, D., \& Cavusgil, S. T. (2006). The impact of information technology on supply chain capabilities and firm performance: A resource-based view. Industrial Marketing Management, 35(4), 493-504.

46. Wu, K. J., Tseng, M. L., Chiu, A. S., \& Lim, M. K. (2017). Achieving competitive advantage through supply chain agility under uncertainty: A novel multi-criteria decision-making structure. International Journal of Production Economics, 190, 96-107.

47. Yang, J. (2014). Supply chain agility: Securing performance for Chinese manufacturers. International Journal of Production Economics, 150, 104-113.

48. Zahra, S. A., Sapienza, H. J., \& Davidsson, P. (2006). Entrepreneurship and dynamic capabilities: A review, model and research agenda. Journal of Management Studies, 43(4), 917-955.

49. Zhang, D. Z. (2011). Towards theory building in agile manufacturing strategies-Case studies of an agility taxonomy. International Journal of Production Economics, 131(1), 303-312.

50. Zollo, M. \& Winter, S. G. (2002). Deliberate learning and the evolution of dynamic capabilities. Organization Science, 13(3), 339351. 